\title{
Educação a distância: uma alternativa para a formação na área de tecnologia assistiva? ${ }^{1}$
}

\section{Distance Education: an alternative for training in the area of assistive technology?}

MIRYAM BONADIU PELOSI

Universidade Federal do Rio de Janeiro

KARINE GUEDES FERREIRA Universidade Federal do Rio de Janeiro

ANDREZA DOS SANTOS MUNARETTI

Universidade Federal do Rio de Janeiro

\author{
JANAÍNA SANTOS NASCIMENTO \\ Universidade Federal do Rio de Janeiro
}

Resumo: A disponibilidade de novas tecnologias modificou a forma como as pessoas trocam informações e se comunicam, e beneficiou aquelas com dificuldades comunicativas, criando oportunidades para as Pessoas com Deficiência. Entretanto, este avanço demanda que os terapeutas ocupacionais aprimorem seus conhecimentos em Tecnologia Assistiva. O objetivo desse estudo foi relatar a experiência de realização de um curso piloto, a distância, em Comunicação Alternativa. Esse foi ofertado na Plataforma Moodle, com carga horária de 30 horas, e contou com 119 inscritos. A avaliação das atividades demonstrou que os alunos compreenderam os tópicos abordados no curso e que foram capazes de desenvolver projetos completos com o software Prancha Fácil e com os aplicativos do Portal Aragonês de Comunicação Aumentativa e Alternativa (ARASAAC). A experiência mostrou que o uso de Ambientes Virtuais de Aprendizagem para a formação de profissionais que trabalham na área de Tecnologia Assistiva possibilita o aprendizado de conhecimento suficiente para a realização de atividades práticas de boa qualidade.

Palavras-chave: Terapia Ocupacional. Tecnologia Assistiva. Educação a Distância.

Abstract: The availability of new technologies has changed the way people exchange information and communicate, and benefited those with communication difficulties, creating opportunities for people with disabilities. However, this advancement has demanded that occupational therapists improve their knowledge about Assistive Technology. The aim of this study was to report the conduction experience of a distance pilot course, in Alternative Communication. It was offered in the Moodle platform, with 30 hours workload, and had 119 subscribers. The evaluation of the activities demonstrated that the students understood the topics that were covered in the course and were able to develop complete projects with the Easy Plank software and with the ARASAAC Portal applications. This experience has shown that the use of Virtual Learning Environments for training professionals who work in Assistive Technology area enables sufficient knowledge of learning to perform practical activities of good quality.

Keywords: Assistive Technology. Occupational Therapy. Distance Education.

PELOSI ${ }_{l}$ M. B.; FERREIRA, K. G, ; MUNARETTI, A. S.; NASCIMENTO, J. S. Educação a distância: uma alternativa para a formaçáo na área de tecnologia ássistiva? Informática na Educação: teoria \& prática, Porto Alegre, v. 21, n. 2, p.45-57, mai./ago. 2018.

1 Projeto financiado pelo Conselho Nacional de Desenvolvimento Científico e Tecnológico - CNPq, Processo: 458633/2013-5 


\section{Introdução}

Pessoas com dificuldades de comunicação oral e/ou escrita podem se beneficiar de recursos, serviços, estratégias e técnicas que as auxiliem a se comunicar de maneira mais funcional, e a isso se dá o nome de Comunicação Alternativa e Ampliada (CAA) (ASHA, 2011; BRYANT; BRYANT, 2012). A Comunicação Alternativa, uma das áreas da Tecnologia Assistiva, torna-se essencial para que as pessoas com dificuldades comunicativas realizem suas atividades do dia a dia e desempenhem seus papéis ocupacionais.

É um aspecto tão importante da vida que a gestão da comunicação das pessoas é uma das áreas de intervenção da Terapia Ocupacional (AOTA, 2014). Mas se, por um lado, o avanço tecnológico criou oportunidades para indivíduos com dificuldades comunicativas, por outro, vem exigindo que os terapeutas ocupacionais aprimorem seus conhecimentos na área de Tecnologia Assistiva.

Os avanços e a disponibilidade de novas tecnologias modificaram a forma como as pessoas administram seus equipamentos, trocam informações e se comunicam umas com as outras. Do mesmo modo, essa tecnologia também tem mudado a maneira como as pessoas ensinam e aprendem. A estrutura de aulas presenciais vem sendo associada a modalidades de ensino a distância, que tem o potencial de abranger, ao mesmo tempo, um número muito maior de alunos.

Essa foi a estratégia pensada para difundir o conhecimento na área de Comunicação Alternativa, com ênfase no software Prancha Fácil, desenvolvido pelo Núcleo de Pesquisa em Tecnologia Assistiva de uma universidade da região sudeste do país. O Prancha Fácil é um programa gratuito, acessível, criado para ser simples, e que oferece a possibilidade de construir pranchas de comunicação para serem impressas ou utilizadas de forma dinâmica no computador. O programa foi desenvolvido para possibilitar que profissionais de diferentes áreas e familiares pudessem produzir atividades para auxiliar o processo de alfabetização e o brincar, e atender à demanda de comunicação de crianças, jovens e adultos em diversos contextos (PELOSI et al, 2016).

A Educação a Distância (EAD) é uma ferramenta para atender um amplo contingente de alunos de forma mais eficaz que outras modalidades, sem redução da qualidade dos serviços oferecidos.

A utilização de novos recursos comunicacionais na EAD torna-se cada vez mais viável, facilitando o acesso à informação em tempo real, de forma globalizada. As áreas de conhecimento de maior concentração dos cursos na modalidade EAD são as de Ciências Sociais e Educação, abrangendo pessoas do sexo feminino, com idade entre 18 e 40 anos, que estudam e trabalham (RANGEL, 2012; RIBEIRO, 2006; ABED, 2012).

Os cursos são realizados em Ambientes Virtuais de Aprendizagem (AVA), que são softwares que armazenam, disponibilizam e administram conteúdo em formato World Wide Web (WWW). Esses ambientes têm como objetivo facilitar o processo de oferta de cursos online, sem que o responsável seja especialista em computação ou tecnologia para elaborar e disponibilizar um curso e acompanhar o desenvolvimento do aluno. No ambiente virtual, são observados alguns fatores, como: as ferramentas, a acessibilidade, o design, a interface escolhida, a avaliação da aprendizagem e as atividades didáticas que implicarão a construção do conhecimento do aluno. As potencialidades dos cursos EAD podem surpreender tanto alunos como professores nos processos de ensino-aprendizagem, mas o principal entrave é a evasão (RANGEL, 2012; RIBEIRO, 2006).

O objetivo do presente estudo foi acompanhar a experiência de aplicação e avaliação de um curso-piloto sobre Comunicação Alternativa realizado em um Ambiente Virtual de Aprendizagem (AVA).

\section{Metodologia}


Trata-se de um estudo descritivo apresentado como relato de experiência onde os dados foram coletados no Ambiente Virtual de Aprendizagem de um curso de formação continuada para alunos, professores e interessados, denominado "Comunicação Alternativa: construindo com o Prancha Fácil". Ele foi ofertado na modalidade a distância, e oferecido por uma universidade da região sudeste do país, com carga horária de 30 horas e tempo de realização de quatro semanas.

O conteúdo foi ofertado na plataforma Moodle e teve o processo de inscrição divulgado pelo Facebook. Os materiais necessários para a produção do curso compreenderam um Texto de Referência e um Guia de Estudo organizado por unidades e seções, com referência a uma série de vídeos, blogs e links relacionados ao tema.

Ao todo, os participantes desenvolveram três atividades práticas, que foram utilizadas como elementos de avaliação da compreensão dos cursistas sobre os temas abordados, além de uma prova final de múltipla escolha. Para a avaliação do curso, foi elaborado um formulário próprio, com 12 perguntas, para as quais foram atribuídas notas de 1 a 5 . As perguntas estavam relacionadas à avaliação da plataforma, fundamentação teórica do curso, atividades práticas propostas, material de apoio, incluindo vídeos, estudos de caso e leituras complementares, aplicabilidade do conteúdo aprendido para a vida profissional do cursista, avaliação do professor tutor e monitores, apresentação e dinâmica do curso, e autoavaliação, considerando a participação e produção, além de críticas e sugestões.

\section{Resultados}

A divulgação do curso no Facebook despertou o interesse de 300 pessoas em participar, contudo, o número que efetivamente se inscreveram foi de 119 cursistas. A inscrição foi um processo que gerou muitas dúvidas para os participantes, sendo necessário o desenvolvimento de vídeos explicativos sobre a forma de realizar o primeiro acesso à plataforma e inúmeras trocas de e-mails com os monitores, para que as inscrições pudessem ser efetivadas. O procedimento variava para alunos que eram da própria universidade, e que já tinham utilizado a plataforma, e para os demais interessados de outras regiões.

O conteúdo do curso foi desenvolvido por um professor especialista na área de Tecnologia Assistiva, e toda a comunicação com os cursistas, incluindo a correção das atividades e feedback aos alunos, foi realizada por esse professor. As duas monitoras que participaram do processo faziam parte do laboratório de Tecnologia Assistiva da universidade, mas apenas apoiaram na inclusão dos alunos interessados na plataforma Moodle. Por se tratar de um curso-piloto, o principal objetivo do estudo foi acompanhar todo o processo do curso de educação a distância, e essas ações envolveram a possibilidade de maior conhecimento dos problemas sinalizados pelos alunos em relação à plataforma, dos conteúdos disponibilizados e das atividades práticas elaboradas.

Para a preparação do curso, foi necessária a elaboração de um Guia de Estudo, que é um roteiro de aula semanal, elaborado a partir do texto de referência, com carga horária estimada de oito horas. O Guia de Estudo foi a base para a preparação dos slides que foram utilizados no Ambiente Virtual de Aprendizagem Moodle.

O Guia de Estudo foi organizado por unidade e seções, com referências nas páginas da web a vídeos curtos postados no YouTube e a links para trechos do Texto de Referência, permitindo assim mais aprofundamento dos tópicos trabalhados. Cada slide não excedeu 10 linhas, incluindo o título.

Além do Guia de estudo, foi necessário elaborar o Texto de Referência, que é o material de estudo do aluno e tem uma característica semelhante a uma apostila e, assim como o Guia de Estudo, precisou ser organizado em unidades e seções. 
A grande diferença de uma aula em um ambiente AVA, em comparação à aula presencial, é que o conteúdo precisa ser explicado o mais didaticamente possível, para que não suscite dúvidas no cursista. Necessariamente o texto de referência deve começar por um pequeno texto de motivação, que desperte o interesse do aluno para aquele tema. As unidades também precisam estar equilibradas, considerando as semanas e a carga horária do módulo. Para dicas sobre outros textos, sites, pesquisas e vídeos, o professor-autor deve indicar com "Saiba mais...".

Além desse material, foram necessários a construção de questões sobre tópicos do módulo, separados pelas semanas de estudo; a indicação de uma atividade prática por unidade; e o esclarecimento dos critérios de avaliação da atividade prática.

Foram desenvolvidos, também, vários vídeos tutoriais sobre os softwares trabalhados, e foi demonstrado como acessar, pesquisar e fazer o download de atividades no Portal Assistiva. O material contou com muitas imagens, a indicação de textos de apoio, vídeos de usuários utilizando diferentes recursos de CAA, vídeos sobre como programar aplicativos e softwares, além de links para blogs e sites.

O curso foi organizado em três módulos. A primeira unidade tratou do conceito de Comunicação Alternativa com ênfase nos símbolos, recursos, estratégias e técnicas. Ao final da unidade, os cursistas foram convidados a construir uma prancha de comunicação para o contexto escolar utilizando o software Prancha Fácil, que deveria ser impressa.

O Prancha Fácil é um software gratuito desenvolvido para ser usado como um sistema de comunicação para crianças jovens e adultos em diferentes contextos como a casa, a escola, o hospital, espaços culturais, e muitos outros. Com ele, é possível fazer pranchas para serem impressas ou utilizadas de forma dinâmica no computador, sem a necessidade de conexão à Internet.

O programa permite o acesso por meio do mouse, tela touchscreen, sistema de varredura, softwares que controlam o movimento da cabeça, como o HeadMouse, e o mouse ocular PCEYE $X$ e Explore permitindo, assim, que pessoas com dificuldades motoras graves possam utilizar o software com facilidade.

As funcionalidades incluem: a biblioteca de símbolos gratuitos do Portal Aragonês de Comunicação Aumentativa e Alternativa (ARASAAC) e a possibilidade de uso de imagens próprias; gravação do próprio som e inclusão de sons pré-gravados; a inserção de vídeos; mudança das cores da tela e da célula do símbolo, modificação do tamanho e posicionamento das letras e muitos modelos de atividades que podem ser utilizados ou modificados facilmente.

A atividade com o software Prancha Fácil foi realizada por 53,8\% dos 119 cursistas inscritos, percentual que correspondeu a 64 pessoas. A maior parte dos alunos $(64,1 \%)$ não teve dificuldade em realizar a tarefa a partir das instruções do Guia de Referência e do apoio dos vídeos instrucionais. As atividades que precisaram de correção apresentavam problemas como símbolos sem borda ou tamanho de letra inadequado $(47,8 \%)$.

A grande maioria dos cursistas que desenvolveu a atividade com o Prancha Fácil (96,9\%) elaborou atividades completas, como mostram as Figuras 1 e 2, e apenas 3,1\% realizaram apenas experiências com o programa. As atividades desenvolvidas utilizaram o programa construindo pranchas de comunicação ou atividades pedagógicas adaptadas. A média final das notas da primeira atividade foi de 99,06, e 92,2\% das pessoas receberam nota 100, a pontuação máxima. 
Figura 1 - Prancha de comunicação elaborada com o software Prancha Fácil

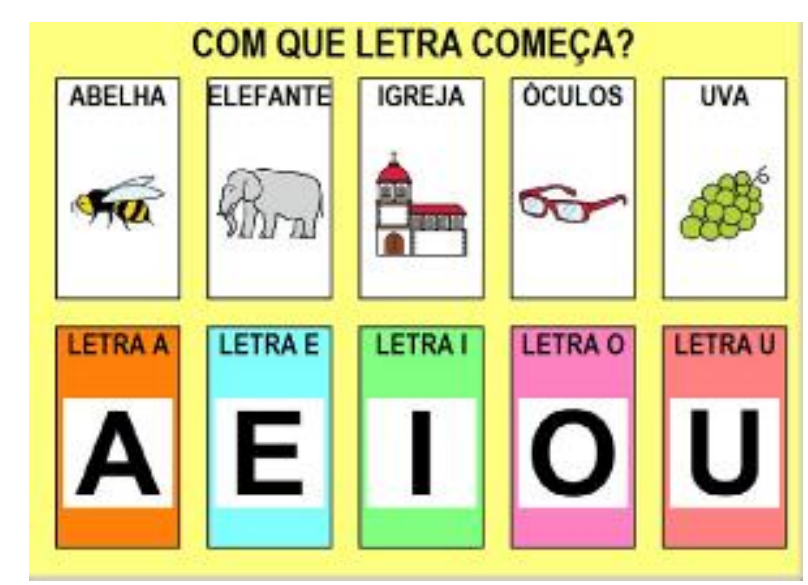

Fonte: Curso EAD de Comunicação Alternativa: construindo com o Prancha Fácil.

Figura 2 - Atividade pedagógica adaptada elaborada com o software Prancha Fácil

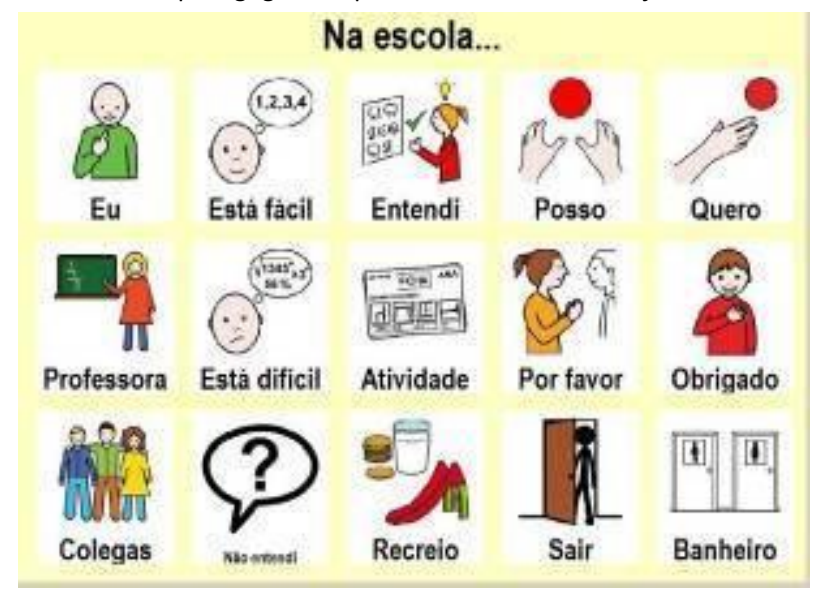

Fonte: Curso EAD de Comunicação Alternativa: construindo com o Prancha Fácil.

A segunda unidade apresentou as regras de seleção do vocabulário para a construção de pranchas de comunicação, e as diferentes maneiras de elaborá-las. Foi apresentado o Portal ARASAAC e alguns dos seus recursos, como a ferramenta de construção de bingos e dominós, para a elaboração de atividades pedagógicas. Ao término da unidade, o aluno foi orientado a desenvolver uma atividade pedagógica utilizando uma dessas ferramentas.

O Portal ARASAAC é um portal na Internet que disponibiliza símbolos pictográficos traduzidos em 15 idiomas, incluindo o português do Brasil. O Portal possui 12 mil pictogramas coloridos, 9500 pictogramas em preto e branco e 1400 fotografias. Além disso, disponibiliza ferramentas online que permitem a construção de pranchas de comunicação, modificação de símbolos, construção de calendários, rotinas diárias, histórias e jogos.

A segunda atividade prática teve a participação de 51 cursistas, que representavam $42,9 \%$ dos inscritos na plataforma. Dentre esses, $72,5 \%$ completaram a atividade proposta construindo jogos elaborados com o número de peças suficiente para a utilização do material. Os demais realizaram apenas experimentos para conhecer a ferramenta, como jogo de bingo com uma cartela ou dominó com menos do que 28 peças. A avaliação final da atividade mostrou que $90,2 \%$ das pessoas alcançaram a nota máxima e que a média geral foi de 98,62. 
Nessa Unidade, os cursistas poderiam escolher qual ferramenta seria utilizada para desenvolver a atividade prática. As Figuras 3, 4 e 5 mostram exemplos de atividades de dominó encadeado, bingo e frases escritas com símbolos.

Figura 3 - Dominó sobre as rotinas diárias elaborado no Portal ARASAAC

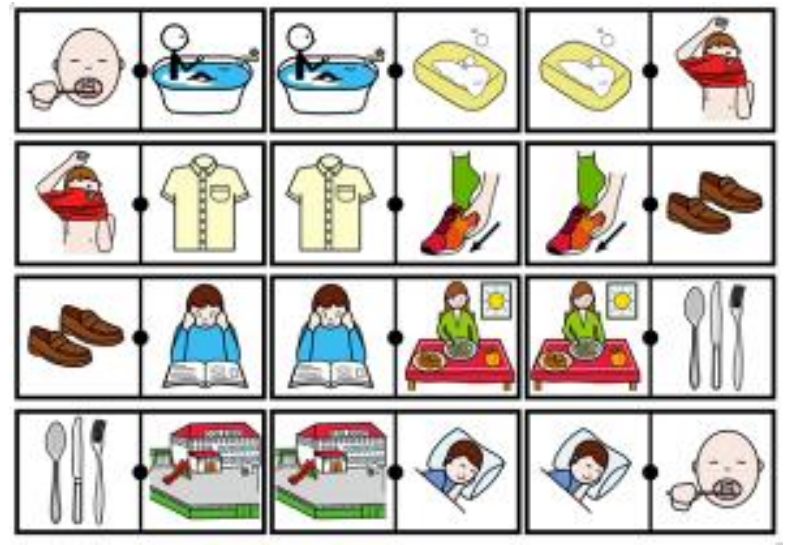

Fonte: Curso EAD de Comunicação Alternativa: construindo com o Prancha Fácil.

Figura 4 - Frase escrita com símbolos elaborada com a ferramenta do Portal ARASAAC

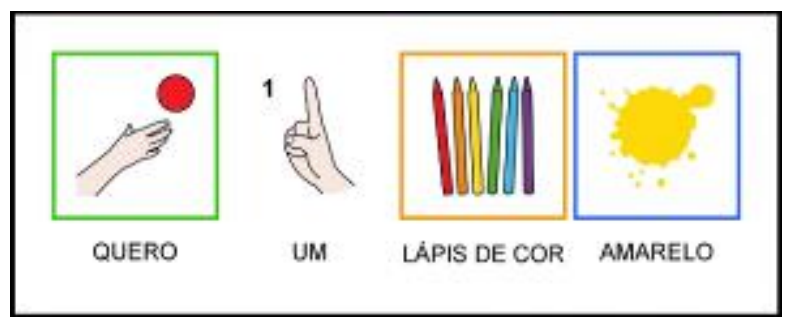

Fonte: Curso EAD de Comunicação Alternativa: construindo com o Prancha Fácil. 
Figura 5 - Bingo elaborado com a ferramenta do Portal ARASAAC

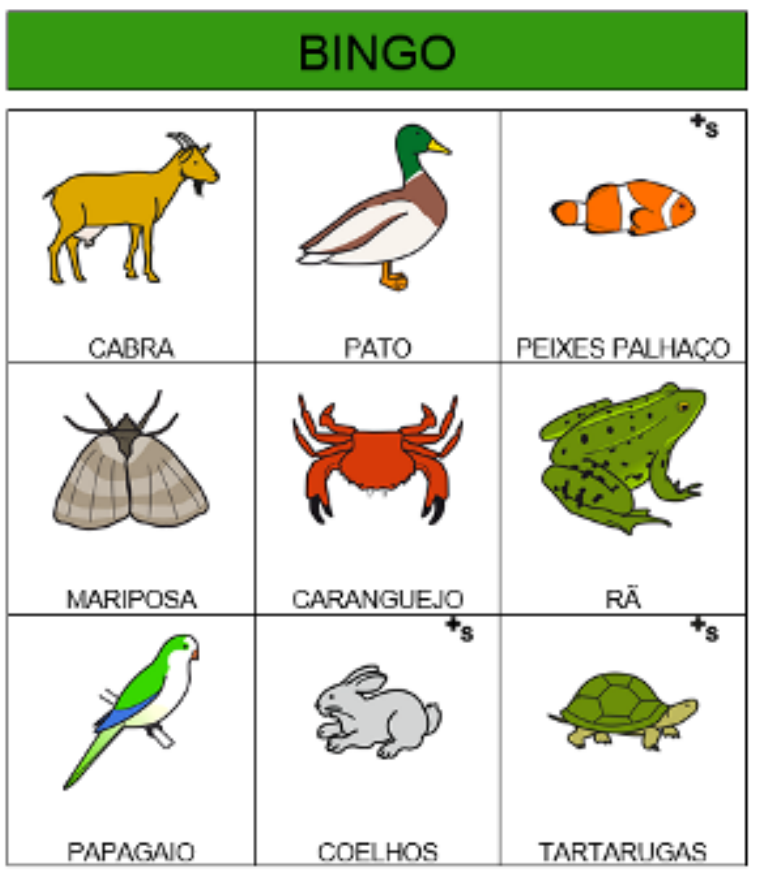

Fonte: Curso EAD de Comunicação Alternativa: construindo com o Prancha Fácil.

A terceira e última unidade apresentou o Portal Assistiva, um banco de atividades que pode ser acessado gratuitamente, e trabalhou os conceitos necessários para a elaboração de uma prancha de comunicação dinâmica com o software Prancha Fácil.

O Portal de Tecnologia Assistiva foi criado a partir das atividades desenvolvidas no Projeto de pesquisa/extensão: Formação em Serviço de Professores de Salas Multifuncionais para o desenvolvimento da Comunicação Alternativa com os alunos com Necessidades Educacionais Especiais (PELOSI et al., 2013).

O projeto teve apoio do Programa "Apoio À Melhoria do Ensino em Escolas Públicas Sediadas no Estado do Rio de Janeiro - 2009" do Edital FAPERJ N. ${ }^{\circ}$ 14/2009 e do Programa PIBEX da UFRJ.

Os 20 professores que participaram dessa formação elaboraram, ao longo de um ano, 400 atividades, incluindo pranchas de comunicação estáticas e dinâmicas, jogos, histórias e atividades pedagógicas adaptadas com símbolos.

De lá para cá, o Portal recebeu contribuições de alunos de graduação de vários cursos da universidade, pesquisadores envolvidos em projetos e disciplinas relacionadas com a área de Tecnologia Assistiva, além de contribuições da comunidade.

A proposta do Portal é a de divulgar a Tecnologia Assistiva e socializar, com profissionais que trabalham com pessoas com deficiência e seus familiares, aplicativos desenvolvidos com diferentes softwares. A Figura 6 mostra a página inicial do Portal Assistiva. 


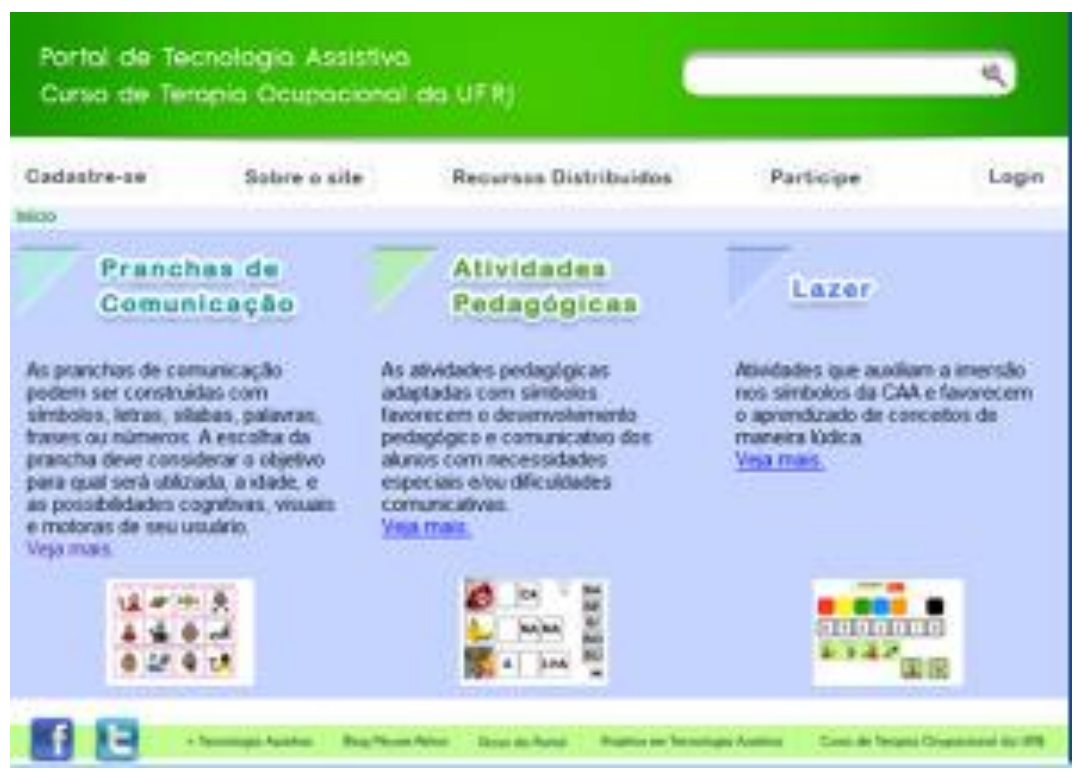

Fonte: Imagem do autor

Para a elaboração da atividade da Unidade III, o cursista deveria ser capaz de fazer o projeto de uma prancha dinâmica, decidir o número de símbolos que deveriam ser apresentados em cada página, selecionar o pictograma na biblioteca de imagens do software ou pesquisar uma imagem do próprio computador, colocar o nome do pictograma e ajustar a fonte do texto, escolher a posição do texto em relação à imagem, inserir borda, gravar o som de cada imagem e interligar uma tela à outra.

O grupo que desenvolveu essa atividade somou 43 pessoas e representou $36,1 \%$ do total dos que se inscreveram na plataforma. A maior parte dos cursistas que finalizaram a atividade $(95,3 \%)$ não teve problemas para enviar a atividade para avaliação, e apenas 4,7\% só conseguiu enviar o material em formato JPEG, inviabilizando a análise do projeto dinâmico. O problema mais comum entre as pranchas encaminhadas foi a ausência de som ou a baixa qualidade da gravação (37,2\%). A média das notas da Unidade III foi de 96,74.

As Figuras de 7 a 10 mostram as várias pranchas de um projeto dinâmico elaborado com o software Prancha Fácil para ser utilizado no computador.

Figura 7 - Página inicial do projeto Vamos Passear

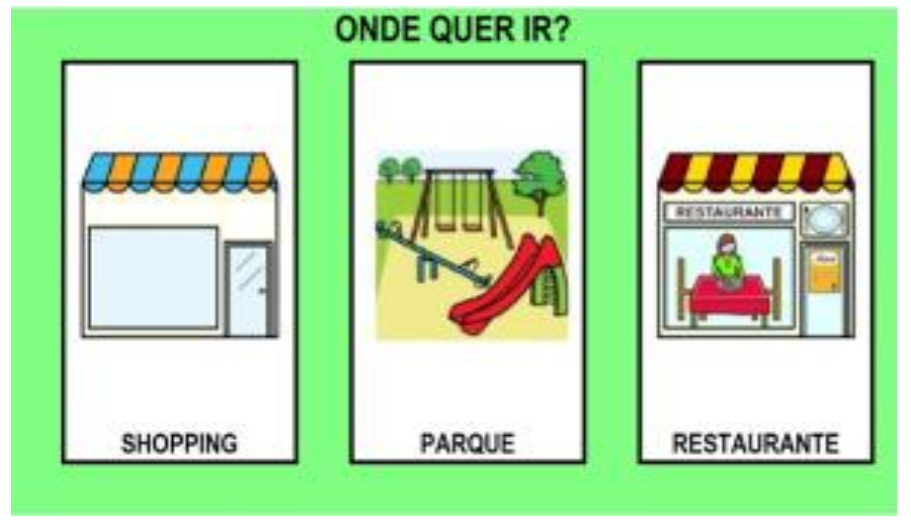

Fonte: Curso EAD de Comunicação Alternativa: construindo com o Prancha Fácil. 
Figura 8 - Ampliação da opção "Shopping"

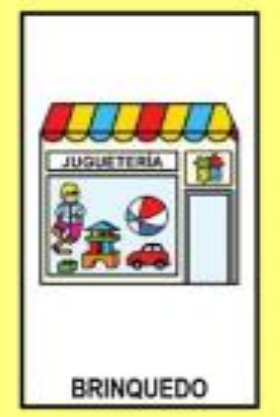

\section{SHOPPING}

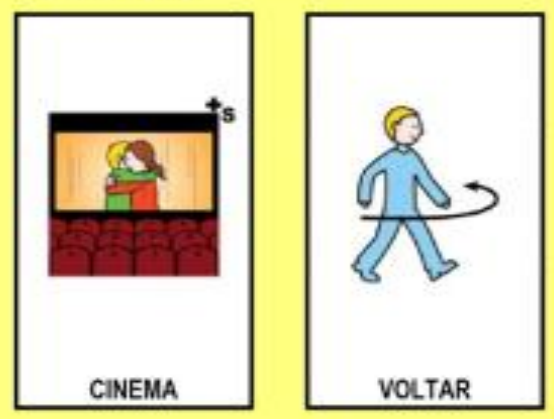

Fonte: Curso EAD de Comunicação Alternativa: construindo com o Prancha Fácil.

Figura 9 - Ampliação da opção "Parque"

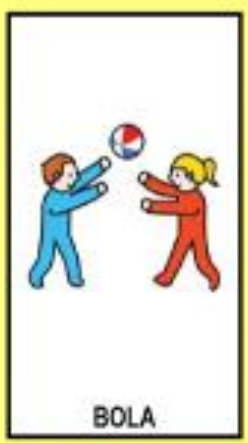

\section{PARQUE}
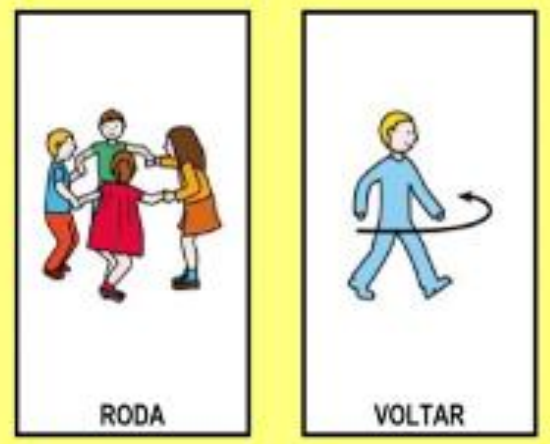

Fonte: Curso EAD de Comunicação Alternativa: construindo com o Prancha Fácil.

Figura 10 - Ampliação da opção "Restaurante"

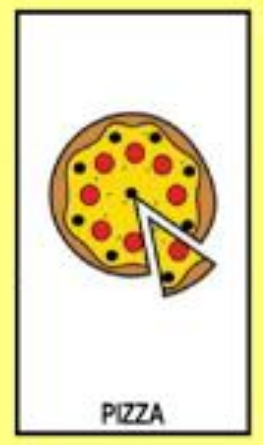

\section{RESTAURANTE}
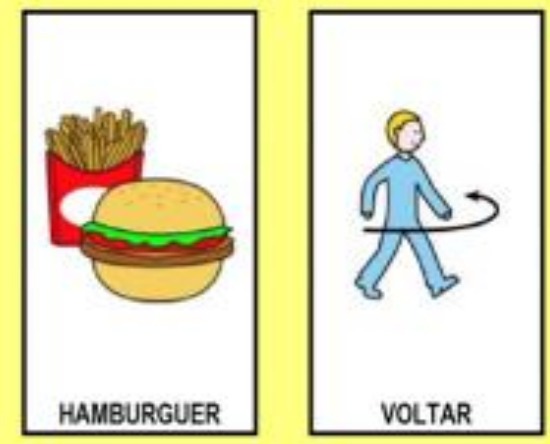

Fonte: Curso EAD de Comunicação Alternativa: construindo com o Prancha Fácil.

A prova de 10 questões de múltipla escolha, avaliação final do curso, contou com a participação de 42 pessoas, 35,3\% dos 119 inicialmente inscritos, sendo que todas alcançaram 
a nota final máxima. Um dos participantes que completou todas as atividades não realizou a prova final.

A avaliação do curso, por parte dos alunos que finalizaram as atividades, mostrou que a dinâmica apresentada, o material de apoio, a fundamentação teórica, as atividades práticas e o suporte do professor instrutor foram excelentes para mais de $80 \%$ deles. Os pontos com menor pontuação foram a dificuldade de acesso à plataforma Moodle e o processo de inscrição.

Como já mencionado, o curso teve 300 pessoas interessadas a partir de sua divulgação no Facebook, mas apenas 119 pessoas se inscreveram na plataforma Moodle. Dessas, um pouco mais da metade, 64 cursistas, acessou a plataforma e finalizou a primeira atividade. A segunda atividade foi finalizada por 51 pessoas e a terceira tarefa por 43 delas. A taxa de evasão, considerando os alunos que acessaram a plataforma, foi de 32,9\%. Apesar da redução do número de participantes no decorrer do curso, a avaliação de cada uma das atividades demonstrou que os cursistas compreenderam os tópicos abordados no curso e que foram capazes de desenvolver projetos completos com o software Prancha Fácil $(96,9 \%)$, e com os aplicativos do Portal ARASAAC $(90,2 \%)$.

\section{Discussão}

A organização de cursos para serem ofertados na modalidade de Educação a Distância necessita de uma preparação detalhada do material que será utilizado. Entre eles estão o Guia de Estudo, o Texto de Referência, a organização de atividades avaliativas conceituais ou práticas, além de vídeos ilustrativos e links para blogs e sites que auxiliem a compreensão dos temas abordados (PELOSI, 2015).

O curso de Comunicação Alternativa foi organizado a partir dessas premissas e os resultados demonstraram que a dinâmica apresentada, o material de apoio, a fundamentação teórica, as atividades práticas e o suporte do professor instrutor foram excelentes para a grande maioria dos cursistas.

No presente estudo, $46,2 \%$ das pessoas que se inscreveram na plataforma não iniciaram o curso ou, se iniciaram, não chegaram a completar a primeira atividade. A evasão de alunos em cursos de Educação a Distância é um dos principais problemas apontados nos estudos da área.

Documento divulgado pela Associação Brasileira de Educação a Distância - ABED, em 2014, aponta que a evasão dos estudantes é o maior obstáculo para o ensino na modalidade a distância. No estudo, foram considerados alunos evadidos os que se inscreveram, mas não iniciaram os cursos na modalidade a distância ou os que abandonaram de uma forma ou outra (ABED, 2014).

Esse estudo mostrou ainda que os principais desafios dessa metodologia compreenderam a resistência dos educadores à modalidade, as dificuldades de adaptação da educação presencial para a educação a distância, a resistência dos alunos ao novo formato e o custo de produção do material (ABED, 2014).

Apesar de não ter sido feita uma pesquisa em relação aos motivos de evasão dos alunos do presente curso, os e-mails encaminhados à coordenadora justificavam a desistência pela falta de disponibilidade de tempo para iniciar ou dar continuidade ao curso, por dificuldades de acessar à rede, somados à proximidade do término do ano, uma vez que o curso foi lançado no mês de novembro.

Diferentes estudos (RIBEIRO, 2006; RANGEL, 2012; ABED, 2012) sinalizam que as principais causas para a evasão são a falta de tempo para o estudo e para participar do curso ao longo da semana, a dificuldade de acesso à Internet, a falta de adaptação à metodologia e o aumento de trabalho ao longo do processo.

No curso em questão, o número elevado de atividades práticas solicitadas pode ter contribuído para o maior abandono dos estudantes, pois além de terem que estudar conceitos relacionados à implementação da Comunicação Alternativa como símbolos, recursos, 
estratégias e técnicas, regras de seleção do vocabulário, se familiarizarem com o Portal ARASAAC e suas ferramentas, e com o uso do Portal Assistiva, tinham que compreender todo o funcionamento do software Prancha Fácil para que pudessem desenvolver pranchas dinâmicas. Sem contar que, a cada semana, os cursistas deveriam postar na plataforma um dos exercícios práticos solicitados.

Estudo realizado por Rangel (2012) mostrou que limitações de acesso à Internet podem impactar no desempenho dos cursistas. Estes dados também foram sinalizados no estudo realizado por Ribeiro (2006), em que apenas $60,7 \%$ concluíram o referido curso. Dentre os participantes que desistiram, as principais justificativas foram a falta de tempo devido ao acúmulo de atividades no período do curso, problemas com o computador e com o provedor de Internet. A taxa de evasão apresentada pelo autor foi de $39 \%$, enquanto a do presente estudo ficou em $46,2 \%$. Embora significativamente maior, os motivos se repetiram. Por outro lado, se considerarmos a evasão dos alunos que efetivamente iniciaram o curso de Comunicação Alternativa, a taxa de evasão foi de 32,9\% mostrando que a desistência ao longo do curso foi bem menor.

Estudos mostram que a taxa de alunos que se inscrevem, mas não iniciam o curso é muito alta, ficando em torno de $50 \%$ (RIBEIRO, 2006), o que corrobora os dados encontrados no presente estudo $(46,2 \%)$. Isso significa dizer que uma grande quantidade de alunos que se inscreve nos cursos a distância, ocupa as vagas dos colegas interessados em adquirir aquele conhecimento, e a metade deles nunca chega a acessar a plataforma. Apesar desse dado alarmante, os autores destacam que os alunos não alegam que o motivo da desistência se deva ao fato do curso não atender às suas expectativas (RIBEIRO, 2006; RANGEL, 2012; ABED, 2012).

Contudo, há experiências que tiveram êxito, como a apresentada por Bardy (2013) no estudo sobre Tecnologia Assistiva, Projetos e Acessibilidade, na qual o índice de evasão foi de apenas $3 \%$, e motivado por problemas pessoais dos cursistas. Nesse curso, a metodologia adotada permitiu que os alunos desenvolvessem atividades compartilhadas, tivessem o apoio dos colegas e a possibilidade de dividir experiências reais de seus contextos de atuação profissional. O curso foi ofertado pela Universidade Aberta do Brasil, com carga horária de 180 horas, dividida em quatro módulos, fez parte de um Programa de Formação Continuada de Professores na Educação Especial e teve por objetivo formar professores dos sistemas estaduais e municipais.

Outra questão apontada nos estudos sobre cursos EAD é a pouca familiaridade de alguns alunos com o ambiente virtual. Estudo realizado por Rangel (2012) mostrou que 16\% dos cursistas que chegaram ao final do curso não conseguiram se sentir à vontade para realizar seus estudos no ambiente virtual. Outros autores evidenciam ser um processo complexo, que exige tempo para aceitação e apropriação por parte dos alunos, e que estes podem abandonar o curso por não se identificarem com a concepção de ensino a distância, que enfatiza a interatividade e a participação ativa (RIBEIRO, 2006; RANGEL, 2012; BARDY, 2013).

A relação entre teoria e prática é fundamental na concepção do curso. Assim como no ensino presencial, também a EAD possibilita a seus estudantes uma rede de aprendizagens permeada pela troca de experiências e, sobretudo, a criação de novos conhecimentos quando utiliza as ferramentas de chat e conferências online com horário previamente agendado.

Para favorecer a adaptação do aluno à plataforma, pode ser necessária a criação de estratégias que auxiliem a sua comunicação com os tutores e o coordenador. No curso de Comunicação Alternativa, os cursistas precisaram compactar suas atividades para que essas pudessem ser anexadas à plataforma. Para minimizar as dificuldades encontradas pelos participantes, foi necessária a elaboração de vídeos explicativos e contato direto com os participantes.

A tutoria é o método utilizado na EAD para dar apoio ao aluno, e é de grande relevância na avaliação do curso. Profissionais de áreas específicas atuam no acompanhamento e na avaliação dos cursistas e precisam estar familiarizados com os temas abordados, além de ter 
domínio da plataforma. Muitos alunos precisam ser orientados e incentivados por seus tutores para que se envolvam ativamente com o conteúdo das aulas e com as atividades. A promoção de debates e fóruns de discussão pode auxiliar na elaboração das tarefas e na construção do conhecimento (GOMES, 2009; BARDY, 2013).

Neste estudo, o tutor principal foi o próprio coordenador do curso e, por essa razão, as dificuldades apresentadas pelos alunos foram rapidamente resolvidas.

A avaliação da compreensão dos cursistas sobre os temas abordados no curso foi feita por meio da produção desenvolvida pelos mesmos. Como os projetos foram postados na plataforma, pode-se verificar que havia coerência na escolha e organização dos pictogramas para a criação das pranchas de comunicação, consistência do número de símbolos nas páginas que compunham o projeto e interligações adequadas nos projetos com o software Prancha Fácil para serem utilizados no computador. Nas atividades desenvolvidas com as ferramentas do Portal ARASAAC também houve adequação na escolha e organização dos pictogramas. A maior parte dos cursistas pensou em soluções que poderiam auxiliar pessoas com dificuldades comunicativas, e não apenas experimentou o uso de aplicativos e softwares de maneira mecânica.

A análise do material produzido mostrou que a organização do curso por módulos possibilitou que os alunos tivessem tempo para realizar projetos mais elaborados e para refletir sobre as necessidades das pessoas com necessidades complexas de comunicação.

\section{Conclusão}

A necessidade de formação de um número cada vez maior de profissionais na área de Tecnologia Assistiva impulsionou a elaboração desse curso-piloto de Comunicação Alternativa, na modalidade de Educação a Distância, com o intuito de experimentar essa modalidade como uma alternativa possível para a formação na área, em especial, no aprendizado do uso de softwares de comunicação.

Os resultados mostraram que, apesar do alto percentual de alunos que se inscreveram e não chegaram a iniciar o curso, o uso de Ambientes Virtuais de Aprendizagem para formação de profissionais que trabalham na área de Tecnologia Assistiva possibilitou o aprendizado de conhecimento suficiente para a realização de atividades práticas de boa qualidade, que poderão ser utilizadas em intervenções junto a pessoas com dificuldades comunicativas em diferentes contextos.

Como estratégia a ser utilizada em cursos futuros, sugere-se a diminuição do número de atividades práticas. A proposta de trabalhar com um projeto único, que possa ser aprofundado ao longo do curso, parece mais adequada para favorecer o engajamento e adesão dos cursistas ao EAD. Para diminuir o percentual de pessoas que se inscrevem por impulso, maior divulgação da temática, metodologia e programa do curso, incluindo as horas necessárias de trabalho semanal, poderá provocar uma inscrição mais consciente e responsável por parte dos interessados.

Estudos futuros que acompanhem as dificuldades encontradas por cursistas na participação de formações na área de Tecnologia Assistiva, e as razões para o abandono, contribuirão para o crescimento do uso da modalidade Educação a Distância para essa área de conhecimento.

\section{Referências}

AOTA - AMERICAN OCCUPATIONAL THERAPY ASSOCIATION. Occupational therapy practice framework: domain and process. American Journal of Occupational Therapy, Rockville, v. 68, n. 6, p. 1-43, 2014.

ABED. Censo EAD.BR: Relatório Analítico da Aprendizagem a Distância no Brasil (2012). Censo EAD.BR. Curitiba: Ibpex, 2013. Disponível em: <. Acesso em 30 ago. 2014. 
ASHA. AMERICAN SPEECH-LANGUAGE-HEARING ASSOCIATION. Augmentative and Alternative communication (AAC). Disponível em: <http://www.asha.org/public/speech/disorders/AAC.htm. >. Acesso em 2 jan. 2015.

BARDY, L. R. et al. Objetos de aprendizagem como recurso pedagógico em contextos inclusivos: subsídios para a formação de professores a distância. Rev. Bras. Educ. Espec. Marilia, v. 19, n. 2, p. 273-288, jun. 2013.

BRYANT, D. P.; BRYANT, B. R. Assistive Technology for People with Disabilities. $2^{\text {a }}$ ed. Boston: Pearson, 2012.

GOMES, S. G. S. Teoria e Prática do Sistema de Acompanhamento em EAD, 2009. Disponível em: <http://ftp.comprasnet.se.gov.br/sead/licitacoes/Pregoes2011/PE091/Anexos/Eventos_modulo_I/topico _ead/Aula_09.pdf>. Acesso em 13 set. 2016.

PELOSI, M. B.; SOUZA, V. L. V.; DIAS, R. C. V.; MENEZES, L. T.; OLIVEIRA, L. M. Os caminhos que levaram à criação do Portal de Tecnologia Assistiva do Curso de Terapia Ocupacional da UFRJ. Cad. Ter. Ocup. UFSCar. São Carlos: UFSCar, v. 21, n. 2, p. 289-298, 2013.

Tecnologia Assistiva voltada para a Formação de Professores no Contexto do AEE. In. L. A. R. Martins e L. G. S. Silva (Orgs). Educação inclusiva: Pesquisa, Formação e Práticas. João Pessoa: Ideia, 2015, p.121 - 135.

.; CARVAlHO, N.; GUEDES, A. L.; Borges, J. A. S. Easy Board - A New approach to the production of alternative communication Boards. In: 17th Biennial Conference of International Society for Augmentative and Alternative Communication (ISAAC), 2016, Toronto. 17th Biennial Conference of International Society for Augmentative and Alternative Communication (ISAAC). Toronto: Isaac, 2016.

RANGEL-S. M. L. et al. Redes de aprendizagem colaborativa: contribuição da Educação a Distância no processo de qualificação de gestores do Sistema Único de Saúde - SUS. Interface (Botucatu), Botucatu, v. 16, n. 41, p. 545-556, jun. 2012.

RIBEIRO, M. A. S.; LOPES, M. H. B. M. Desenvolvimento, aplicação e avaliação de um curso a distância sobre tratamento de feridas. Rev. Latino-Am. Enfermagem, Ribeirão Preto, v. 14, n. 1, p. 77-84, fev. 2006.

Recebido em dezembro de 2016

Aprovado para publicação em julho de 2018

Miryam Bonadiu Pelosi

Professora Associada do Departamento de Terapia Ocupacional da Universidade Federal do Rio de Janeiro - UFRJ, Brasil, E-mail: miryampelosi@ufrj.br

\section{Karine Guedes Ferreira}

Terapeuta Ocupacional, Graduada pela Universidade Federal do Rio de Janeiro - UFRJ, Brasil, E-mail: kguerreira5@gmail.com

Andreza dos Santos Munaretti

Terapeuta Ocupacional, Graduada pela Universidade Federal do Rio de Janeiro - UFRJ, Brasil, E-mail: munarettiandreza@gmail.com

Janaína Santos Nascimento

Professora Assitente do Departamento de Terapia Ocupacional da Universidade Federal do Rio de Janeiro - UFRJ, Brasil, E-mail: jananascimento.to@gmail.com 